\section{Dement Geriatr Cogn Disord Extra 2012;2:418-432}

\begin{tabular}{l|l}
\hline DOI: $10.1159 / 000338228$ & $\odot$ 2012 S. Karger AG, Basel \\
\hline Published online: October 5, 2012 & www.kargercom/dee
\end{tabular}

This is an Open Access article licensed under the terms of the Creative Commons AttributionNonCommercial-NoDerivs 3.0 License (www.karger.com/OA-license), applicable to the online version of the article only. Distribution for non-commercial purposes only.

\title{
Compliance and Caregiver Satisfaction in Alzheimer's Disease: Results from the AXEPT Study
}

\author{
Roberto Bernabei ${ }^{a}$ Paolo Maria Rossini $^{b} \quad$ Luigi Di Cioccio $^{c}$ \\ Daniela Gragnaniello ${ }^{d}$ Emilio Luda di Cortemigliae \\ Mahmood Attar ${ }^{f}$ Delia Colombo ${ }^{f}$
}

a Dipartimento di Scienze Geriatriche, Gerontologiche e Fisiatriche, Centro di Medicina dell'Invecchiamento, and ' ${ }^{b}$ Dipartimento di Neuroscienze, Università Cattolica del Sacro Cuore, Rome, 'Dipartimento di Geriatria, Ospedale Santa Scolastica, Cassino, dUnità Operativa di Neurologia, Dipartimento di Neuroscienze e Riabilitazione, Università Sant'Anna, Ferrara, ' Divisione di Neurologia, Ospedale di Rivoli, Rivoli, and ${ }^{\mathrm{f}}$ Novartis Farma S.p.A., Origgio, Italy

\section{Key Words}

Alzheimer's disease $\cdot$ Compliance $\cdot$ Satisfaction $\cdot$ Drug formulation $\cdot$ AXEPT study

\begin{abstract}
Background/Aims: According to experimental data, a transdermal application is preferred by caregivers of Alzheimer's disease (AD) patients compared with oral medications. The AXEPT study compared compliance to treatment among community-dwelling patients with mild-tomoderate AD treated with transdermal application compared to oral medications and caregiver satisfaction in a real clinical setting. Methods: Data from 45 memory clinics in Italy were collected between September 8, 2010 and January 31, 2011. Compliance to treatment and caregiver satisfaction were measured using the Caregiver Medication Interview. Results: A total of 855 AD patients and their caregivers participated in the study. Nearly $80 \%$ of caregivers of patients on patch were not concerned about adherence to treatment compared with $64 \%$ of caregivers of patients on oral drugs. Among caregivers of patients on patch, $94 \%$ did not report any difficulties in remembering to administer treatment compared with $73 \%$ of caregivers of patients on oral medications. The highest level of compliance and satisfaction was reported by caregivers of patients on transdermal application. Conclusion: Caregivers of patients treated with a transdermal application appeared to be more satisfied and reported a higher level of compliance than caregivers of patients receiving anti-AD oral medications.
\end{abstract}

Copyright $\odot 2012$ S. Karger AG, Basel 


\section{Introduction}

Alzheimer's disease (AD) is a neurodegenerative disorder which causes a progressive and irreversible loss of cognition and physical function. Currently, over 35 million people worldwide are affected by AD. The number of AD patients will increase sharply in the near future, and it has been estimated that over 80 million individuals will be diagnosed with this condition by the year $2040[1,2]$.

To date, no cure is available to modify the progression of $\mathrm{AD}$, although available pharmacological treatments have been proven to positively control cognitive and functional symptoms of the disease and improve quality of life of patients and their families for the time they are responsive to treatment [3].

Most often, care for $\mathrm{AD}$ patients is provided by informal caregivers including relatives and friends [1]. Caregivers are individuals who are called to assist patients in their activities of daily living, to administer medications to them and to deal with the patients' progressive personality change and physical, cognitive and emotional deterioration. Such aspects make providing care to people with $\mathrm{AD}$ a burdensome experience which affects the physical and psychological state of caregivers and their quality of life. Managing and administering medications to $\mathrm{AD}$ patients may substantially contribute to the caregivers' workload and distress $[4,5]$. Compliance to treatments and efficacy of medications may depend on how well caregivers are able to manage drug administrations. The caregivers' satisfaction with treatments is crucial for a good compliance to treatments, and it has been associated with an increased likelihood of positive clinical outcomes, decreased need of sedatives and anxiolytics, and delayed patient institutionalization [6-10].

Currently, there are four medications approved for the treatment of AD by regulatory authorities. Three are acetylcholinesterase inhibitors (AChEIs) including donepezil, rivastigmine and galantamine; the fourth is memantine, an N-methyl-D-aspartic acid receptor antagonist. These medications are all available in oral formulation. Among these drugs, rivastigmine is the only one available in transdermal (patch) application. Since the rivastigmine patch has been marketed, experimental data from randomized clinical trials have suggested that the transdermal application would be preferred by caregivers of AD patients compared to oral medications $[11,12]$. To date, no information is available regarding patient compliance to treatment and caregiver satisfaction with respect to different formulations of $\mathrm{AD}$ medications in a real clinical setting.

The present study aimed at comparing compliance to treatment of community-dwelling patients with mild-to-moderate AD treated with transdermal application compared to oral formulation drugs and caregiver satisfaction in a real clinical setting. The secondary purpose of the study was to provide a full description of sociodemographic and clinical characteristics of mild-to-moderate AD patients and to draw a sociodemographic profile of their caregivers. A sub-study was conducted to perform the linguistic and psychometric validation of the Caregiver Medication Interview (CMI), which is the instrument adopted in the current investigation to assess patient compliance to treatment and caregiver satisfaction.

\section{Methods}

\section{Study Design}

The AXEPT study consisted of a main study, which was conducted to primarily compare patient compliance to treatment and caregiver satisfaction with respect to oral and transdermal formulations of anti-AD medications, and a sub-study, which was conducted to validate the CMI instrument. The main study had an observational, cross-sectional, multicenter de-

\section{(1)}


sign. In the sub-study, a sample of participants was observed longitudinally and assessed with the CMI at the baseline visit and 1 week later (follow-up visit) to measure the psychometric properties of this instrument.

\section{Study Population}

The study was conducted in 45 memory clinics uniformly distributed throughout Italy between September 8, 2010 and January 31, 2011. Patients with AD were considered eligible for participation if: (a) they had a Mini-Mental State Examination (MMSE) score between 18 and 26 at the screening visit; (b) they were 18 years old or more; (c) they signed an informed consent, and (d) they were treated either with AChEIs or memantine in monotherapy regimens, and such treatment was initiated 4-6 months prior the baseline visit as either the first anti-AD treatment ever received or a new drug option after switching from an old treatment. All the above-mentioned inclusion criteria had to be met for patients to be enrolled in the study. Patients were excluded from the study if they were treated with a combination of AChEIs or with AChEIs plus memantine.

Caregivers had to be present at the baseline visit and had to provide care to the patients at least $4 \mathrm{~h}$ per day for at least 4 months prior to the baseline visit. They had to speak and understand the Italian language and to be able to answer a questionnaire including a numeric rating scale.

\section{Patient and Caregiver Assessment}

Participants in the main study were assessed at one point in time during the baseline visit. Participant assessment was conducted by site physicians who received specific training on the study procedures during a centralized investigator meeting. Information was collected by direct interviews with patients and caregivers and extracted from medical charts. The patients' and caregivers' sociodemographic characteristics were reported. The caregivers were asked about the daily amount of time spent providing care to patients. Information on the patients' weight, height, blood pressure, heart rate, disease duration, swallowing difficulties, medical history and concomitant gastrointestinal or dermatological symptoms or diseases was also collected. The cognitive status of patients was assessed using the MMSE [13]. The Activities of Daily Living scale (ADLs), scoring from 0 (total dependence) to 6 (total independence), was used to evaluate the patients' functional status [14].

Data on the patients' current anti-AD pharmacological treatment were recorded, including the drug ingredient, dose, formulation, start date of treatment and eventual reason for switching to a different medication. The patients' use of concomitant medications with particular respect to psychotropic drugs was also assessed.

\section{Outcome Assessment}

The patient compliance to treatment and the caregiver satisfaction were assessed using the CMI. The CMI is an ad hoc questionnaire developed for the purpose of the AXEPT study. It was initially developed in the English version by the AXEPT researchers as an instrument which could have been used internationally. It is available in two forms, one designed to be used in case of oral treatment and one designed to be used in case of transdermal applications. It consists of three questions directed to the caregiver and exploring the ease of administration, the global compliance and the satisfaction relative to the treatment the patient is receiving. For questions on compliance and satisfaction, the caregiver has to indicate, on a numeric rating scale, a score between 0 and 10 , with 0 being the lowest degree and 10 the highest degree of compliance and satisfaction. The CMI form is reported in Appendix 1. 
Data collected from direct interviews with caregivers and from medical charts during the baseline visit were used to assess the characteristics of mild-to-moderate $\mathrm{AD}$ patients and their caregivers.

\section{Statistical Analysis}

According to the methods proposed by Divine et al. [15] for estimating the sample size for the Wilcoxon-Mann-Whitney test, it has been calculated that a sample of 730 participants was required to observe a $\mathrm{P}(\mathrm{X}>\mathrm{Y})$ equal to 0.57 with a power of 0.90 and a 0.05 type $\mathrm{I}$ error. Given that $\mathrm{X}$ and $\mathrm{Y}$ are random observations from the two distributions being compared (transdermal and oral formulation), $\mathrm{P}(\mathrm{X}>\mathrm{Y})$ represents the probability that $\mathrm{X}$ is greater than $\mathrm{Y}$. Since previous data were missing, it has been conservatively assumed that $\mathrm{P}(\mathrm{X}>\mathrm{Y})$ equals 0.57 , under the null hypothesis that $\mathrm{P}(\mathrm{X}>\mathrm{Y})$ equals 0.50 . A zero variance associated with ties and an allocation ratio of 3 to 4 between the transdermal and the oral formulation according to data on prescription patterns in Italy have also been assumed.

Characteristics of the study participants according to the type of drug formulation received were assessed using descriptive statistics. Compliance to treatment and caregiver satisfaction were described according to the type of drug formulation (oral or transdermal). Descriptive statistics included mean, standard deviation, median, mode, quantiles and interquartile range. Comparison between patient compliance and caregiver satisfaction according to the type of drug formulation was conducted using the Wilcoxon-Mann-Whitney test.

Statistical analysis was performed using SAS v 9.1.2.

\section{Validation}

For the purpose of the current study, the English version of the CMI was translated into the Italian language, and a linguistic and psychometric validation of the Italian version was performed.

The linguistic validation process included the following steps:

- forward translation of the English CMI into Italian: two forward translations were produced by two independent professional translators who were native Italian speakers;

- reconciliation: creation of a preliminary combined version (reconciled version) on which both translators and investigators agreed;

- backward translation of the Italian reconciled version into English: the preliminary Italian version was translated back into English by a professional translator who was a native English speaker and had no access to the original version of the instrument;

- comparison between the backward translated version with the original English version; mistranslations and inaccuracies were detected and the preliminary Italian version was revised accordingly in a consensus meeting including the backward translator and the investigators;

- comprehension test: the Italian revised version of the CMI was administered to a sample of 18 caregivers of patients who were potential study participants according to the inclusion criteria; these caregivers were identified from the three expected highest recruiting sites; this was a qualitative examination performed to determine possible problems in the respondents' understanding of the instructions;

- creation of a final Italian version by the investigators and implementation of this instrument in the study.

The psychometric evaluation of the translated CMI was then conducted in a sub-sample of 188 caregivers participating in the study and selected by the six expected highest recruiting sites. The CMI was administered to the sub-study caregivers during the baseline evaluation and 1 week later. The reliability of the instrument was evaluated by measuring its internal consistency, expressed by Cronbach's $\alpha$, and its test-retest reliability, expressed by the 
intraclass correlation coefficient (ICC) and the Spearman correlation coefficient ( $\rho$ ). No gold standard among the instruments which measure compliance to treatment and caregivers' satisfaction is available in the literature. Therefore, the convergent validity was evaluated comparing the CMI scores with the responses obtained from the same caregivers who were administered with a Visual Analogue Scale (VAS). For the purpose of this study, a VAS including a $10-\mathrm{cm}$ line with one extreme indicating the lowest and the other extreme indicating the highest compliance and satisfaction was used. The comprehension test of this instrument was conducted during the linguistic validation process. The ICC and Spearman's $\rho$ were measured to estimate the convergent validity of the Italian version of the CMI compared with the VAS.

\section{Results}

Patients and caregivers consecutively visiting the participating memory clinics since the beginning of the study were screened for enrolment. The duration of the screening period was 5 months, and a competitive enrolment was allowed. A total of 896 patients and their caregivers were screened; 41 of them were excluded because they did not meet the inclusion criteria. The final sample for this study consisted of 855 patients and their caregivers.

Sociodemographic, cognitive, functional and clinical characteristics of the study patients by type of drug formulation received are reported in table 1 . The mean age of patients was 77 years in both groups, and over $60 \%$ were female. Both groups showed a mild-to-moderate cognitive impairment (mean MMSE score 21.0) and a good level of preserved functional abilities (mean ADL score 5.0). Over $80 \%$ of patients had one or more medical conditions associated with AD. Cardiovascular diseases were highly prevalent in both groups, with nearly $50 \%$ of patients affected by hypertension and $20 \%$ diagnosed with any cardiac disease. Patients on oral medications were more likely to be diagnosed with psychiatric illnesses such as major depression, bipolar disorder and schizophrenia than patients on patch (14.6 vs. 7.9\%). However, the patients' compliance to treatment and the caregivers' satisfaction by type of drug formulation did not change after stratifying the sample on the presence of psychiatric illnesses. Moreover, correlation analyses showed that psychiatric illnesses were not associated with the type of drug formulation and with compliance and satisfaction. The prevalence of gastrointestinal diseases was slightly higher among patients treated with oral medications compared to those treated with the rivastigmine patch. Dermatological conditions were rarely reported, with a slightly increased prevalence in the group receiving oral medications. Other conditions including chronic obstructive pulmonary disease, asthma, cancer, swallowing problems and renal or liver failure were infrequent and equally distributed in the two groups.

The estimated mean time from the onset of symptoms to AD diagnosis was nearly 2 years in both groups. Over $17 \%$ of patients in both groups had switched from a previous anti-AD medication to the current one received at the study time. The most frequently reported medication changes were from either donepezil or oral rivastigmine to patch (40\%) and from either patch or oral rivastigmine or donepezil to memantine (34\%). The most frequently reported reason for switching was low tolerability of the previous treatment. With respect to other psychotropic medications, $30 \%$ of patients on oral medications and $26 \%$ of patients on patch were taking antidepressants mostly belonging to the class of selective serotonin re-uptake inhibitors. Antipsychotic prescription was not frequent in the study population, with more atypical than conventional medications used in both groups. A low prevalence of use was also reported for benzodiazepines and anticonvulsants in both groups. 
Table 1. Sociodemographic, functional and clinical characteristics of patients stratified by type of anti-AD drug formulation

\begin{tabular}{lcc}
\hline & $\begin{array}{c}\text { Oral } \\
(\mathrm{n}=461)\end{array}$ & $\begin{array}{c}\text { Transdermal } \\
(\mathrm{n}=394)\end{array}$ \\
\hline Mean age, years & 77.9 & 77.6 \\
Female gender, \% & 63.2 & 64.1 \\
Mean education, years & 6.6 & 6.4 \\
Mean BMI & 25.6 & 25.6 \\
Mean ADL score & 5.0 & 5.0 \\
Mean MMSE score & 21.0 & 2.7 \\
Any comorbidities, \% & 85.8 & 83.7 \\
Hypertension, \% & 46.6 & 53.4 \\
Any cardiac disease, \% & 21.6 & 17.6 \\
Dyslipidemia, \% & 17.9 & 17.6 \\
Diabetes, \% & 11.1 & 15.0 \\
Cerebrovascular diseases, \% & 6.8 & 6.1 \\
Psychiatric illnesses, \% & 14.6 & 7.9 \\
Gastrointestinal diseases, \% & 7.0 & 5.1 \\
Dermatological diseases, \% & 1.1 & 0.3 \\
COPD/asthma, \% & 6.4 & 4.4 \\
Swallowing difficulties, \% & 3.5 & 3.8 \\
Cancer, \% & 2.8 & 2.8 \\
Renal failure, \% & 2.6 & 2.0 \\
Liver failure, \% & 0.9 & 1.5 \\
Mean time to diagnosis from AD symptom onset, years & 1.7 & 1.8 \\
Mean duration of AD, months & 11.3 & 11.3 \\
Switching from different AChEIs or memantine, \% & 17.9 & 17.4 \\
Antipsychotic use, \% & & \\
$\quad$ Atypical & 8.1 & 6.4 \\
Conventional & 3.9 & 4.3 \\
Antidepressant use, \% & 30.1 & 26.0 \\
Benzodiazepine use, \% & 7.0 & 8.1 \\
Anticonvulsant use, \% & 3.9 & 2.8 \\
\hline
\end{tabular}

Characteristics of the caregivers in the study according to the type of drug formulation their patients were receiving are reported in table 2 . The mean age of the caregivers was 58 years, and over $70 \%$ were female. Over $95 \%$ of the caregivers were relatives, and more than half of them were living with the patient. The mean time spent providing care reported by caregivers in both groups was around $12 \mathrm{~h}$ per day. The rivastigmine patch was the most frequently prescribed anti-AD drug in the study population. Over $46 \%(\mathrm{n}=396)$ of the study patients were on rivastigmine patch, while $54 \%(\mathrm{n}=461)$ were receiving any type of oral anti-AD drugs. With respect to oral drugs, $25 \%$ of patients were treated with donepezil and $21 \%$ were receiving memantine. Only $4 \%$ of patients were treated with galantamine and $4 \%$ with oral rivastigmine. The median and the mode in addition to the range of the daily drug dose are reported in table 3 . Medians and modes are presented rather than means because of their clinical significance.

Nearly $80 \%$ of caregivers of patients on patch were not concerned about patient adherence to anti-AD medical treatment compared to $64 \%$ of caregivers of patients on oral medications (fig. 1a). Among caregivers of patients on patch, $94 \%$ of them did not report any difficulties in remembering to administer treatment compared to $73 \%$ of caregivers of patients on oral medications (fig. 1b). Both compliance to treatment and satisfaction were signifi- 
Table 2. Sociodemographic characteristics of caregivers stratified by type of anti-AD drug formulation

\begin{tabular}{|c|c|c|}
\hline \multicolumn{3}{|c|}{ Dement Geriatr Cogn Disord Extra 2012;2:418-432 } \\
\hline $\begin{array}{l}\text { DOI: } 10.1159 / 000338228 \\
\text { Published online: October 5, } 2012\end{array}$ & \multicolumn{2}{|c|}{$\begin{array}{l}\text { @ } 2012 \text { S. Karger AG, Basel } \\
\text { www.karger.com/dee }\end{array}$} \\
\hline \multicolumn{3}{|c|}{$\begin{array}{l}\text { Bernabei et al.: Compliance and Caregiver Satisfaction in Alzheimer's Disease: Results } \\
\text { from the AXEPT Study }\end{array}$} \\
\hline & $\begin{array}{l}\text { Oral } \\
(n=461)\end{array}$ & $\begin{array}{l}\text { Transdermal } \\
(\mathrm{n}=394)\end{array}$ \\
\hline Mean age, years & 58.9 & 58.7 \\
\hline Female gender, $\%$ & 71.2 & 70.0 \\
\hline Mean education, years & 10.5 & 10.8 \\
\hline \multicolumn{3}{|l|}{ Relationship with patient, $\%$} \\
\hline Son/daughter & 48.2 & 49.6 \\
\hline Spouse & 35.5 & 34.3 \\
\hline Brother/sister & 2.8 & 3.6 \\
\hline Other relative & 9.6 & 7.9 \\
\hline Other ${ }^{1}$ & 1.1 & 0.8 \\
\hline Caregiver lives with patient, \% & 55.0 & 56.7 \\
\hline Mean duration of caring, years & 2.53 & 2.32 \\
\hline Mean time spent caring, h/day & 12.1 & 11.8 \\
\hline
\end{tabular}

${ }^{1}$ Including formal caregiver, friend and volunteer.

Table 3. Drug regimens among patients on AChEIs and memantine

\begin{tabular}{lclll}
\hline & $\begin{array}{l}\text { Number of } \\
\text { patients (\%) }\end{array}$ & $\begin{array}{l}\text { Median of daily } \\
\text { dose, mg }\end{array}$ & $\begin{array}{l}\text { Mode of daily } \\
\text { dose, mg }\end{array}$ & $\begin{array}{l}\text { Range of daily } \\
\text { dose, mg }\end{array}$ \\
\hline Donepezil & $220(25.7)$ & 5.0 & 5.0 & $5.0-10.0$ \\
Rivastigmine (oral) & $31(3.6)$ & 6.0 & 6.0 & $1.5-12.0$ \\
Rivastigmine (transdermal) & $394(46.1)$ & 4.6 & 4.6 & $4.6-9.5$ \\
Galantamine & $33(3.9)$ & 8.0 & 8.0 & $8.0-24.0$ \\
Memantine & $177(20.7)$ & 20.0 & 20.0 & $5.0-20.0$ \\
\hline
\end{tabular}

cantly higher in the group treated with the rivastigmine patch compared to the group on oral medications (table 4). Nearly $90 \%$ of caregivers of patients on transdermal application versus $78 \%$ of caregivers of patients on oral medications reported a score between 9 and 10 at the CMI question on compliance. Over $60 \%$ of caregivers of patients treated with the patch compared to $46 \%$ of caregivers of patients on oral medications reported a score between 9 and 10 at the CMI question on satisfaction.

The translated version of the CMI showed a high level of internal consistency (Cronbach's $\alpha=0.74$ ) and a high test-retest reliability (ICC $=0.96$ and $\rho=0.94$ for items assessing compliance; ICC $=0.98$ and $\rho=0.97$ for items assessing satisfaction). Convergent validity of the instrument compared with the VAS was also high (ICC $=0.79$ and $\rho=0.72$ for items assessing compliance; ICC $=0.92$ and $\rho=0.92$ for items assessing satisfaction).

\section{Discussion}

Findings from the AXEPT study indicate that the use of a transdermal application may improve patient compliance to anti-AD treatment and caregiver satisfaction. These results are in line with previous experimental data which highlighted the benefits of a transdermal application for patients and caregivers. Specifically, more than $70 \%$ of the 1,059 caregivers of AD patients included in the IDEAL trial preferred the patch over capsules for drug delivery [12]. 
Bernabei et al.: Compliance and Caregiver Satisfaction in Alzheimer's Disease: Results from the AXEPT Study

Fig. 1. Results from questions la and $1 \mathrm{~b}$ of the CMI. a CMI question 1a. During the past 1 week of therapy with the oral/patch medication for Alzheimer's dementia, I was concerned that my patient missed taking his/ her capsule/patch medication. b CMI question 1b. During the past 1 week of therapy with the oral/patch medication for $\mathrm{Alz}$ heimer's dementia, I found it difficult to remember to administer capsule/patch medication.
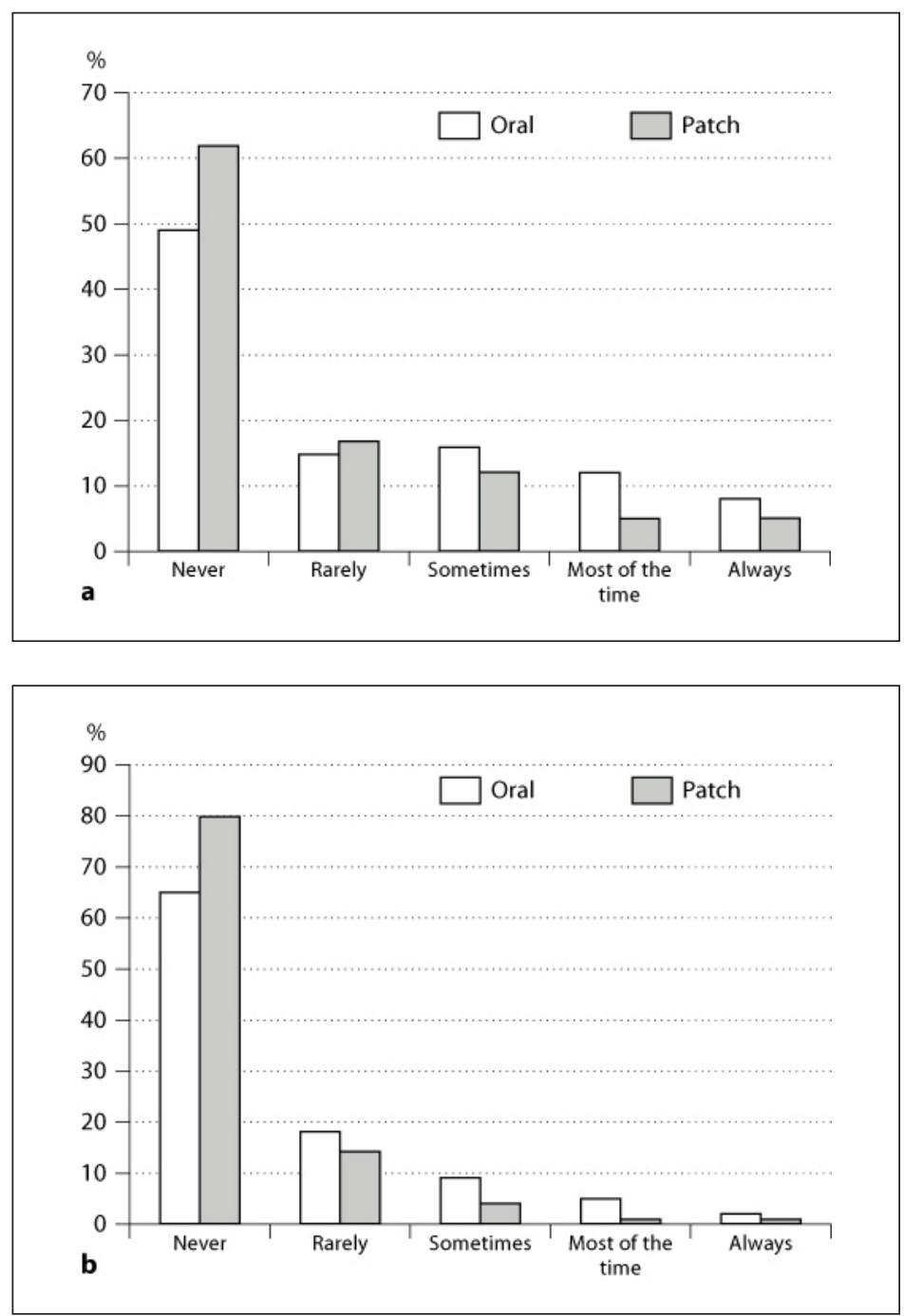

Table 4. Compliance to AD treatment and satisfaction reported by caregivers of patients receiving oral and transdermal formulation on a scale from 0 to 10 (CMI questions 2 and 3)

\begin{tabular}{llll}
\hline & Oral & Transdermal & $p$ \\
\hline Compliance & $9.09 \pm 1.56$ & $9.53 \pm 1.20$ & $<0.0001$ \\
Satisfaction & $7.88 \pm 2.16$ & $8.42 \pm 2.02$ & $<0.0001$ \\
\hline
\end{tabular}

Caregivers reported that their preference for the patch was based on the ease of use and following the schedule, which was eventually related to spare of time and reduced workload. The only previous large observational study investigating caregiver satisfaction with drug treatment in $\mathrm{AD}$ suggested that donepezil orally disintegrating tablets may have been preferred by caregivers; however, this study did not include patients on rivastigmine patch [16]. Such results appear to support the current hypothesis that new effective drug formulations may be preferred by caregivers of $\mathrm{AD}$ patients due to the ease and convenience of administration. 
from the AXEPT Study

Several reasons may explain caregivers' preference towards transdermal applications. It has been shown that the use of the rivastigmine patch is associated with reduced side effects and access to optimal dosages with possible improved efficacy due to constant drug delivery, steady plasmatic drug levels and prolonged cholinesterase inhibition [11, 17-19]. In general, the patch represents a user-friendly mode of drug delivery in geriatric patients who are likely to present with multimorbidity and complex polypharmacy [20, 21]. The potential for overdose due to erroneous multiple administrations may be reduced by using a transdermal application [22, 23]. Finally, the patch provides caregivers with a visual reminder that the medication has been correctly administered, thus helping improve patient compliance to treatment [24]. All these advantages may relieve the strain among caregivers in managing drug administration while improving treatment compliance and effectiveness.

Recently, the WHO has recommended studies focusing on the role of the caregiver and particularly investigating the level of caregiver satisfaction in relation to daily workload and drug administration [25]. Also, the FDA has stated that effective health outcomes in AD should be identified taking into account the needs of both patients and caregivers. In this respect, the caregivers' perspective may provide unique insight into clinical research because of their own experience with this condition [26].

Caregiver satisfaction and preference are directly related to compliance to treatment. Cognitive and functional impairment, behavioral symptoms and susceptibility to side effects make compliance to drug regimens in AD patients particularly challenging. It has been estimated that over $70 \%$ of $\mathrm{AD}$ patients require assistance in managing and taking medications [27]. The development and implementation of strategies to help caregivers administrate medications to their patients may indeed reduce the strain related to such tasks and increase their level of satisfaction with the care delivered. A reduced level of caregiver burden and distress has also been associated with a decreased risk of developing behavioral symptoms in $\mathrm{AD}$ patients and with an overall improved quality of life for their families [6, 28, 29]. Such positive effects result in a more prolonged in-home care provision for patients, with an overall reduction of costs of institutionalization $[10,30]$.

Several interesting findings derived from the description of the study patients' and caregivers' characteristics. The study population included patients with multimorbidity who were relatively preserved in their functional abilities, as it may have been expected in consideration of their mild-to-moderate level of cognitive impairment. Cardiovascular diseases and metabolic conditions such as diabetes and dyslipidemia were highly prevalent in our study patients, and this is in accordance with a growing body of literature which indicates that $\mathrm{AD}$ patients are likely to have an even worse cardiovascular and metabolic profile compared to elderly individuals who are not cognitively impaired [31-35]. The management of comorbidities represents an additional contribution to the overall burden of care, requiring caregivers to monitor medical symptoms and signs and administer complex drug therapy regimens.

In our study patients, the time interval between first appearance of symptoms and AD diagnosis was nearly 2 years. This estimate is in line with previous European data indicating that for a clinical diagnosis of AD nearly 3 years are required in the UK, 2 years in France and Spain and less than 1 year in Germany [36]. The role of families and general practitioners has been recognized as crucial to the process of early identification of AD symptoms, and public health interventions to target possible barriers to an early diagnosis have been proposed [37-39]. The benefits related to an early identification of AD are widely recognized [40]. An early diagnosis allows to provide medical treatments which are most effective in the early stages of the disease, to implement adequate multidisciplinary interventions and to offer tailored socioeconomic support and services to patients and their families [41]. 
The sociodemographic profile of caregivers of community-dwelling patients with mildto-moderate $\mathrm{AD}$ has been described in this study. Caregivers are likely to be women of middle or old age, mostly daughters or spouses, living with the patients. They spend half a day, 7 days per week in providing assistance to the patients. The presence of a formal caregiver was extremely rare in the study. This is in line with previous epidemiological data indicating that family caregivers are those who provide most of the care and social support to the AD patients, thus being daily confronted with the psychological and socioeconomic burden of the disease [5]. The needs of these people are among the most urgent public health issues of our society and need to be addressed by tailored interventions aimed at providing social, financial and psychological support [42].

This study has several limitations. The cross-sectional study design does not make possible to establish any temporal relationship between the exposure to a particular drug formulation and the level of compliance to treatment and caregiver satisfaction reported. Residual confounding is possible. Data on concomitant medications other than psychotropic drugs were not collected. Also, no information was gathered regarding the presence and severity of behavioral and psychological symptoms of dementia. The instrument used to assess the patient compliance and caregiver satisfaction is based on a report of the caregivers' perspectives, which may not necessarily correspond to the patients' opinions. Although all caregivers in the study reported to administer medications to their patients, it is not possible to exclude that some patients may have self-administered treatments. Finally, results have been derived from a sample of community-dwelling mild-to-moderate AD patients and their caregivers in Italy and they may not be extendable to other populations.

\section{Conclusion}

The current study has provided evidence regarding patient compliance to and caregiver satisfaction with $\mathrm{AD}$ pharmacological treatments derived from the observation of a real clinical setting. Caregivers of patients treated with a transdermal application appeared to be more satisfied and reported higher levels of compliance to treatment than caregivers of patients receiving anti-AD oral medications. These findings indicate that new convenient modes of drug administration may be appreciated by caregivers and may contribute to reduce their daily workload, thus producing beneficial effects for the patients and their families. Clinicians should consider such evidence together with efficacy and safety data and the patients' individual clinical profile when choosing the best medical treatment option for persons with $\mathrm{AD}$.

\section{Acknowledgement}

This research was funded by Novartis Farma S.p.A.

\section{Disclosure Statement}

Dr. Attar and Dr. Colombo are employees of Novartis Farma S.p.A. 


\section{Appendix 1}

\section{Caregiver Medication Interview - Oral Form}

The following questions ask about your opinion about the capsule medication used by the patient with Alzheimer's dementia for whom you provide care.

Please answer all of the questions as honestly as you can and without help from anyone. There are no wrong answers.

Taking your medication in the dose and at the times prescribed can be very important to the action of the medication. During the past 1 week of therapy with the oral medication for Alzheimer's dementia, to the best of your knowledge:

1. Check $\square$ one answer for each question below:

Always Most of the Sometimes Rarely Never time

a. I was concerned that my patient misses taking his/her capsule medication

b. I found it difficult to remember to administer the capsule medication

2. Please think about compliance with the oral medication, which means taking the medication as it is prescribed on a daily basis. Please rate the overall compliance with taking the oral medication on a scale from 0 to 10

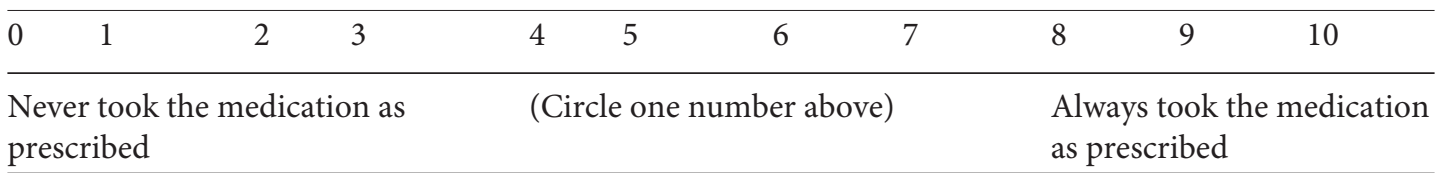

3. Taking all things into account, how satisfied or dissatisfied are you with the oral medication?

\begin{tabular}{lrrrrrrrrr}
\hline 0 & 2 & 3 & 4 & 5 & 6 & 7 & 8 & 9 & 10 \\
\hline Extremely dissatisfied & & & (Circle one number above) & & Extremely satisfied \\
\hline
\end{tabular}


from the AXEPT Study

\section{Caregiver Medication Questionnaire (Patch)}

The following questions ask about your opinion about the treatment received by the patient with Alzheimer's dementia for whom you provide care.

Please answer all of the questions as honestly as you can and without help from anyone. There are no wrong answers.

Taking your medication in the dose and at the times prescribed can be very important to the action of the medication. During the past 1 week of therapy with the patch medication for Alzheimer's dementia, to the best of your knowledge:

1. Check $\square$ one answer for each question below:

Always Most of the Sometimes Rarely Never time

a. I was concerned that my patient missed taking his/her patch medication

b. I found it difficult to remember to administer the patch medication

2. Please think about compliance with the patch, which means administering the patch as it is prescribed on a daily basis. Please rate the overall compliance with administering the patch on a scale from 0 to 10 :

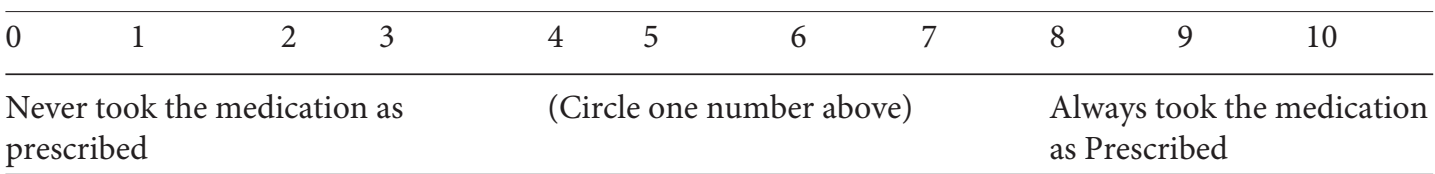

3. Taking all things into account, how satisfied or dissatisfied are you with the patch?

\begin{tabular}{|c|c|c|c|c|c|c|c|c|c|c|}
\hline 0 & 1 & 2 & 3 & 4 & 5 & 6 & 7 & 8 & 9 & 10 \\
\hline
\end{tabular}

\section{Appendix 2}

\section{The AXEPT Study Group}

Roberto Bernabei from Università Cattolica del Sacro Cuore, Roma; Daniela Gragnaniello from Università Sant'Anna, Ferrara; Emilio Luda di Cortemiglia from Ospedale di Rivoli, Rivoli; Paolo Maria Rossini from Università Cattolica del Sacro Cuore, Roma; Emanuele Cassetta from Ospedale Fatebenefratelli, Roma; Alfonso Iudice from Ospedale Santa Chiara, Pisa; Luca Cipriani from Istituto Nazionale Riposo e Cura per Anziani (INRCA), Roma; Alberto Pilotto from Casa Sollievo della Sofferenza, San Giovanni Rotondo; Luigi Di Cioccio from Ospedale Santa Scolastica, Cassino; Claudia Bauco from Servizio Geriatrico 
Integrato 'Dottore Angelico', Aquino; Maria Lia Lunardelli from Policlinico S.Orsola Malpighi, Bologna; Niccolò Marchionni from Università degli studi di Firenze, Firenze; Vito Ferrara from Ospedale Regionale F. Miulli, Acquaviva delle Fonti; Mario Barbagallo, from Università di Palermo, Palermo; Maurizio Russotto from Ospedali Riuniti Villa Sofia Cervello, Palermo; Salvatore Ferrara from Azienda Sanitaria Provinciale di Siracusa, Siracusa; Massimo Franceschi from MultiMedica Holding, Castellanza; Giancarlo Comi from Fondazione San Raffele del Monte Tabor, Milano; Carlo Valente from Azienda Ospedaliera USL 4, Prato; Antonio Lacetera from Ospedale Santa Croce, Fano; Evelina Bianchi from Ospedale Civile San Bortolo, Vicenza; Domenico Consoli from Ospedale G. Jazzolino, Vibo Valentia; Flavio Devetag from Ospedale Santa Maria del Prato, Feltre; Piero Secreto from Casa di Cura Beata Vergine della Consolata Fatebenefratelli, San Maurizio Canavese; Marinella Turla from Ospedale Vallecamonica, Esine; Gianpaolo Ben from Ospedale Civile San Martino, Belluno; Francesco Saverio Caserta from Assistenza Anziani ASL Napoli 1, Napoli; Fabio Di Stefano from ASL VCO Omegna, Omegna; Massimo Zanasi from Ospedali Riuniti, Foggia; Ciro Mundi from Ospedali Riuniti, Foggia; Mauro Minervini from Opera Don Uva, Bisceglie; Sandra Fanfoni from Ospedale Nuovo Regina Margherita, Roma; Carlo Serrati from Ospedale San Martino, Genova; Stefania Boschi from Policlinico Le Scotte, Siena; Cristina Paci from Ospedale Civile Madonna del Soccorso, San Benedetto del Tronto; Leonardo Cocito from Università degli Studi di Genova, Genova; Carlo De Lena from Università degli Studi di Roma La Sapienza, Roma; Lucilla Parnetti from Università di Perugia, Perugia; Lino Pasqui from Ospedale Civile di Monselice, Monselice; Maria Giovanna Marrosu from Policlinico Universitario di Monserrato, Monserrato; Edoardo Dal Monte from Ospedale Civile Salute degli Infermi, Faenza; Antonio Tetto from Ospedale San Leopoldo Mandic, Merate; Giovanni Giannelli from Centro Esperto ASL Cesena, Cesena; Stefano Viola from Ospedale Civile San Pio da Pietralcina, Vasto; Carlo Sabba from Ospedale Policlinico Consorziale, Bari, Italy.

\section{References}

-1 Alzheimer's Association; Thies W, Bleiler L: 2011 Alzheimer's disease facts and figures. Alzheimers Dement 2011;7:208-244.

-2 Ferri CP, Prince M, Brayne C, Brodaty H, Fratiglioni L, Ganguli M, Hall K, Hasegawa K, Hendrie H, Huang Y, Jorm A, Mathers C, Menezes PR, Rimmer E, Scazufca M; Alzheimer's Disease International: Global prevalence of dementia: a Delphi consensus study. Lancet 2005;366:2112-2117.

-3 Massoud F, Léger GC: Pharmacological treatment of Alzheimer disease. Can J Psychiatry 2011;56: 579-588.

-4 Slattum PW, Johnson MA: Caregiver burden in Alzheimer’s disease. Consult Pharm 2004;19:352362.

-5 Brodaty H, Green A: Defining the role of the caregiver in Alzheimer's disease treatment. Drugs Aging 2002;19:891-898.

-6 Belle SH, Burgio L, Burns R, Coon D, Czaja SJ, Gallagher-Thompson D, Gitlin LN, Klinger J, Koepke KM, Lee CC, Martindale-Adams J, Nichols L, Schulz R, Stahl S, Stevens A, Winter L, Zhang S: Enhancing the quality of life of dementia caregivers from different ethnic or racial groups: a randomized, controlled trial. Annals Intern Med 2006;145:727-738.

-7 Mittleman MS, Roth DL, Clay OJ, Haley WE: Preserving health of Alzheimer caregivers: impact of a spouse caregiver intervention. Am J Geriatr Psychiatry 2007;15:780-789.

-8 Schulz R, Beach SR: Caregiving as a risk factor for mortality: the Caregiver Health Effects Study. JAMA 1999;282:2215-2219.

-9 Gilley DW, Farran CJ, MCann J, Bienias JL, Evans DA: Efficacy of two psychosocial interventions on caregiver distress to dementia behavioral symptoms. Gerontologist 2005;45:616.

10 Ernst R, Hay JW: The US economic and social costs of Alzheimer's disease revisited. Am J Public Health 1994;84:1261-1264. 
11 Winblad B, Grossberg G, Frölich L, Farlow M, Zechner S, Nagel J, Lane R: IDEAL: a 6-month, doubleblind, placebo-controlled study of the first skin patch for Alzheimer disease. Neurology 2007;69(4 suppl 1):S14-S22.

- 12 Blesa R, Ballard C, Orgogozo JM, Lane R, Thomas SK: Caregiver preference for rivastigmine patches versus capsules for the treatment of Alzheimer disease. Neurology 2007;69(4 suppl 1):S23-S28.

-13 Folstein MF, Folstein FE, McHugh PR: 'Mini-mental state': a practical method for grading the cognitive state of patients for the clinician. J Psychiatr Res 1975;12:189-201.

14 Katz S, Akpom CA: 12 Index of ADL. Med Care 1976;14(5 suppl):116-118.

-15 Divine G, Kapke A, Havstad S, Joseph CL: Exemplary dataset sample size calculation for WilcoxonMann-Whitney tests. Stat Med 2010;29:108-115.

-16 Sevilla C, Jiménez Caballero PE, Alfonso V, González-Adalid M: Current treatments of Alzheimer disease: are main caregivers satisfied with the drug treatments received by their patients? Dement Geriatr Cogn Disord 2009;28:196-205.

-17 Kurz A, Falow M, Lefecre G: Pharmacokinetics of a novel transdermal rivastigmine patch for the treatment of Alzheimer's disease: a review. Int J Clin Pract 2009;63:799-805.

18 Birks J, Grimley Evans J, Tsolaki M, Holt FE: Rivastigmine for Alzheimer's disease. Cochrane Database Syst Rev 2009:CD001191.

$\checkmark 19$ Dhillon S: Rivastigmine transdermal patch: a review of its use in the management of dementia of the Alzheimer's type. Drugs 2011;71:1209-1231.

20 Small G, Dubois B: A review of compliance to treatment in Alzheimer's disease: potential benefits of a transdermal patch. Curr Med Res Opin 2007;23:2705-2713.

-21 Priano L, Gasco MR, Mauro A: Transdermal treatment options for neurological disorders: impact on the elderly. Drugs Aging 2006;23:357-375.

-22 Grossberg G, Sadowsky C, Fröstl H, Frölich L, Nagel J, Tekin S, Zechner S, Ros J, Orgogozo JM: Safety and tolerability of the rivastigmine patch: results of a 28 -week open-label extension. Alzheimer Dis Assoc Disord 2009;23:158-164.

-23 Darreh-Shori T, Jelic V: Safety and tolerability of transdermal and oral rivastigmine in Alzheimer's disease and Parkinson's disease dementia. Expert Opin Drug Saf 2010;9:167-176.

-24 Grossberg GT, Sadowsky C, Olin JT: Rivastigmine transdermal system for the treatment of mild to moderate Alzheimer's disease. Int J Clin Pract 2010;64:651-660.

25 WHO Report 2008. Available at www.who.int (accessed September 2011).

26 Guidance for Industry: Patient Reported Outcome Measures: Use in Medical Product Development to Support Labelling Claims. FDA website. February 2006. Available at: www.fda.gov/cder/ guidance/5460dft.pdf (accessed September 2011).

27 Alzheimer's Association and National Alliance for Caregiving, 2004 National Survey.

-28 Sink KM, Covinsky KE, Barnes DE, Newcomer RJ, Yaffe K: Caregiver characteristics are associated with neuropsychiatric symptoms of dementia. J Am Geriatr Soc 2006;54:796-803.

-29 Cipriani G, Vedovello M, Nuti A, Di Fiorino M: Aggressive behavior in patients with dementia: correlates and management. Geriatr Gerontol Int 2011;11:408-413.

-30 Ten CW, Tan LF, Luo N, Ng WY, Yap P: Why family caregivers choose to institutionalize a loved one with dementia: a Singapore perspective. Dement Geriatr Cogn Disord 2010;30:509-516.

-31 Löppönen MK, Isoaho RE, Räihä IJ, Vahlberg TJ, Loikas SM, Takala TI, Puolijoki H, Irjala KM, Kivelä SL: Undiagnosed diseases in patients with dementia - a potential target group for intervention. Dement Geriatr Cogn Disord 2004;18:321-329.

- 32 Duthie A, Chew D, Soiza RL: Non-psychiatric comorbidity associated with Alzheimer's disease. QJM 2011;104:913-920.

-33 Gorelick PB, Scuteri A, Black SE, Decarli C, Greenberg SM, Iadecola C, Launer LJ, Laurent S, Lopez OL, Nyenhuis D, Petersen RC, Schneider JA, Tzourio C, Arnett DK, Bennett DA, Chui HC, Higashida RT, Lindquist R, Nilsson PM, Roman GC, Sellke FW, Seshadri S; American Heart Association Stroke Council, Council on Epidemiology and Prevention, Council on Cardiovascular Nursing, Council on Cardiovascular Radiology and Intervention, and Council on Cardiovascular Surgery and Anesthesia: Vascular contributions to cognitive impairment and dementia: a statement for healthcare professionals from the American Heart Association/American Stroke Association. Stroke 2011; 42:2672-2713.

-34 Murray IV, Proza JF, Sohrabji F, Lawler JM: Vascular and metabolic dysfunction in Alzheimer's disease: a review. Exp Biol Med (Maywood) 2011;236:772-782. 
-35 Garcia-Lara JM, Aguillar-Navarro S, Guetierrez-Robledo LM, Avila-Funes JA: The metabolic syndrome, diabetes, and Alzheimer's disease. Rev Invest Clin 2010;62:343-349.

-36 Ahmad S, Orrel M, Lliffe S, Gracie A: GPs' attitudes, awareness, and practice regarding early diagnosis of dementia. Br J Gen Pract 2010;60:360-365.

-37 Martinez-Lage P, Frolich L, Knox S, Berthet K: Assessing physician attitudes and perceptions of Alzheimer's disease across Europe. J Nutr Health Aging 2010;14:537-544.

- 38 Doraiswamy PM, Steffens DC, Pitchumoni S, Tabrizi S: Early recognition of Alzheimer's disease: what is consensual? What is controversial? What is practical? J Clin Psychiatry 1998;59(suppl 13):618.

39 van Vliet D, de Vugt ME, Bakker C, Koopmans RT, Pijnenburg YA, Vernooij-Dassen MJ, Verhey FR: Caregivers' perspectives on the pre-diagnostic period in early onset dementia: a long and winding road. Int Psychogeriatr 2011;1:1-12.

-40 Seltzer B: Cholinesterase inhibitors in the clinical management of Alzheimer's disease: importance of early and persistent treatment. J Int Med Res 2006;34:339-347.

-41 Weimer DL, Sager MA: Early identification and treatment of Alzheimer's disease: social and fiscal outcomes. Alzheimers Dement 2009;5:215-226.

-42 Schwarzkopf L, Menn P, Kunz S, Holle R, Lauterberg J, Marx P, Mehlig H, Wunder S, Leidl R, Donath C, Graessel E: Costs of care for dementia patients in community setting: an analysis for mild and moderate disease stage. Value Health 2011;14:827-835. 